\title{
Isolation of Volatiles Compounds in Banana by HS-SPME: Optimization for the Whole Fruit and Pulp
}

\author{
Heliofábia Virgínia de V. Facundo, Deborah S. Garruti, Beatriz R. Cordenunsi, and Franco M. Lajolo
}

\begin{abstract}
The best conditions for the isolation of banana volatiles by headspace solid phase microextraction (HS-SPME) were determined for the intact whole fruit (with peel) and for the pulp only. Optimization of isolation conditions was carried out using a Central Composite Rotational Design based on Response Surface Methodology with two factors: time needed to reach equilibrium in the headspace and the fiber exposure time. Samples were analyzed by GC-MS. The criteria were higher number of peaks and greater total area of the chromatogram. The best conditions for isolating volatiles from the headspace of whole fruits were $140 \mathrm{~min}$ headspace equilibrium and $120 \mathrm{~min}$ fiber exposure, while for the banana pulp the best conditions were 15 and $60 \mathrm{~min}$ for equilibrium and exposure times, respectively. The results suggest that the whole fruit and pulp have very similar qualitative volatile profile in ripe banana.
\end{abstract}

Index Terms-Central composite rotational design, musa acuminata L., response surface methodology.

\section{INTRODUCTION}

Banana, a fruit rich in nutrients with good flavor, is widely consumed throughout the world [1]. According to the Food and Agriculture Organization of the United Nations (FAO), banana is the main fruit in international trade and one of the most popular fruits in the world. This fruit industry is an important source of income, employment and export earnings for developing countries in Latin America, the Caribbean, Asia and Africa, and is responsible for creating many jobs, both in agricultural and urban areas [2].

Aroma and flavor of fruits are determinant factors in their consumption. Chemically, the aroma and flavor are given by the presence of volatile compounds that impress the olfactory receptors. With regard to banana, its pleasant and peculiar flavor has been the subject of several studies over the past 40 years. More than 150 volatile compounds from several chemical classes have been identified, including esters, ketones, terpenes and aldehydes. Mainly isoamyl and isobutyl esters together with 2-pentanone are the compounds commonly found in larger quantities in banana samples [1].

The separation of volatile compounds from the food matrix (also called isolation) is critical, since these components are typically thermolabile. By a small amount of heating, they may undergo a number of undesirable chemical reactions,

Manuscript received on October 14, 2012; revised January 18, 2012. This work had financial support from CNPq (Process 470813/2009-1) and FAPESP (Process 2009/14958-6 with the scholarship).

Heliofábia Virgínia de V. Facundo, Beatriz R. Cordenunsi, and Franco M. Lajolo are with the Department of Food Science and Experimental Nutrition, University of São Paulo, Av. Prof. Lineu Prestes, 580, Bloco 14, São Paulo-SP, 05508-900, Brazil (e-mail: hojak@usp.br).

Deborah S. Garruti is with the Embrapa Agroindústria Tropical-CNPAT, Av. Dra. Sara Mesquita, 2270, Bairro Pici, Fortaleza-CE, 60511-110, Brazil (e-mail: deborah.garruti@embrapa.br). such as oxidation and rearrangement, causing the volatile profile to become very different from the original sample. Thus, a good isolation method must be efficient, mild, simple and fast, besides using a single step to separate and concentrate the volatile fraction, with the lowest possible manipulation and cost [3].

A solvent-free, cheap, fast and versatile technique for the isolation of organic compounds was developed in 1990 by Arthur \& Pawliszyn [4] - the Solid Phase Microextraction (SPME). It consists of a fused silica fiber coated with a polymeric stationary phase that is placed during a period of time (exposure time) either into a liquid sample or into the headspace above the liquid or solid matrix after some time to reach equilibrium (equilibrium time). The method involves two processes: the partition of analytes between the matrix (or its headspace) and the coating and the thermal desorption of analytes into the gas chromatograph injector equipped with an appropriate inserter [5], [6].

Some authors have used the response surface to optimize the conditions for the extraction of volatile compounds in foods with good results [7], [8]. The Response Surface Methodology (RSM) is an important statistical and mathematical technique, useful for the modeling and standardization of analyses in which a response of interest is influenced by several factors and the goal is just to optimize this response [9].

Therefore, the aim of this study was to determine the optimal conditions of equilibrium time and exposure time for banana volatiles isolation by the headspace solid phase microextraction (HS-SPME) technique, not only for the pulp, but also for the intact whole fruit.

\section{MAterials AND MethodS}

\section{A. Samples}

One hundred units of ripe bananas cv. Nanicão (Musa acuminata, AAA) treated with ethylene were obtained at a local market (CEAGESP - Companhia de Entrepostos e Armazéns Gerais de São Paulo) in São Paulo, Brazil. The fruits were stored in chambers at $19{ }^{\circ} \mathrm{C}$ until the assays.

\section{B. Sample Preparation and SPME Procedures}

Volatiles isolation was carried out at room temperature $\left(25^{\circ} \mathrm{C}\right)$. The SPME fiber was 50/30 $\mu \mathrm{m}$ DVB/CAR/PDMS (divinylbenzene/carboxen/polydimethylsiloxane), obtained from Supelco (Sigma-Aldrich, Bellefonte, PA, USA). The fiber was preconditioned at $250{ }^{\circ} \mathrm{C}$ for $30 \mathrm{~min}$ and was manually inserted into the headspace of the sample's recipient.

For the volatiles analysis of intact whole fruits, $1 \mathrm{~kg}$ of bananas was enclosed in $3 \mathrm{~L}$ jars, five fingers per jar 
approximately (Fig. 1A). For the volatiles analysis of banana pulp (Fig. 1B), fresh banana slices were homogenized (Turrax) with distilled water and sodium chloride (Merck) $(20 \% \mathrm{w} / \mathrm{w})$ to make banana juice at $33.3 \%(\mathrm{w} / \mathrm{w})$. An aliquot of $16 \mathrm{~g}$ of juice was transferred into a $30 \mathrm{~mL}$ vial sealed with a Teflon septum and a plastic cap and remained under agitation with a magnetic stir bar during all isolation procedures.

The ranges of equilibrium time $\left(T_{e q}\right)$ and exposure time $\left(T_{\text {exp }}\right)$ for both methodologies (whole fruit and banana pulp) were based on experimental designs (Section C).

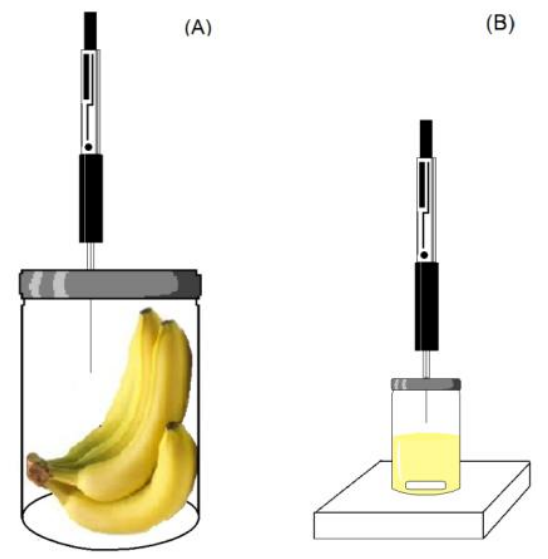

Fig. 1. Representation of the isolation of banana volatile compounds from whole fruits (A) and banana pulp (B) by HS-SPME.

\section{Experimental Design}

Optimization of the HS-SPME conditions was carried out using a Central Composite Rotational Design (CCRD; factorial $2^{2}$ ) based on the Response Surface Methodology (RSM) with four axial points $(\alpha=1.41)$ including three replicates at the central point. The equilibrium time and exposure time were the independent factors studied at different levels. The choice of experimental levels was based on results obtained from the preliminary tests. The complete matrix of the experimental designs with the codified levels and true values are shown in Tables I and II, for whole fruits and banana pulp, respectively. Eleven assays each were carried out randomly and analyzed by gas chromatography.

An experiment was done previously by increasing the temperature by fixing both factors $\left(T_{e q}=15 \mathrm{~min}\right.$ and $T_{\text {exp }}=45$ min) in the pulp sample to verify the influence of the temperature on volatile profile.

\section{Gas Chromatography/Mass Spectrometry (GC-MS) Conditions}

The SPME fiber was injected directly into a Hewlett Packard 6890 (Agilent Technologies Inc., Santa Clara, USA) gas chromatograph-mass spectrometer (GC-MS) and held for $15 \mathrm{~min}$ in order to effect desorption of volatile compounds. The injection port was lined with a $0.75 \mathrm{~mm}$ i.d. splitless glass inserter and maintained at $200{ }^{\circ} \mathrm{C}$. Compounds were separated using a capillary column Supelcowax 10 (30 m x $0.25 \mathrm{~mm}$ x $0.25 \mu \mathrm{m}$ ) from Supelco Inc. (Bellefonte, PA, USA) with helium as the carrier gas at a flow rate of $1.0 \mathrm{mLmin}^{-1}$. The oven temperature was programmed to rise from $50{ }^{\circ} \mathrm{C}$ to $150{ }^{\circ} \mathrm{C}$ at $2^{\circ} \mathrm{C} / \mathrm{min}[10]$ and the total $\mathrm{GC}$ run time was $55 \mathrm{~min}$ MS transfer line was maintained at $290{ }^{\circ} \mathrm{C}$, ionization energy was $70 \mathrm{eV}$, and mass range was $50-550 \mathrm{~m} / \mathrm{z}$. The retention indexes were calculated according to the equation of $\mathrm{V}$ an den
Dool and Kratz [11] for a homologous series of alkanes (C9-C22) injected under the same GC-MS conditions. The volatile compounds were identified by comparing the results obtained with the reference mass spectra from the NIST library (NIST98, version 2.0, Gaithersburg, USA) using the criterion of at least $75 \%$ similarity for the mass spectra. The total volatile production was estimated by the number of peaks and the sum of all peak areas detected in the chromatogram (total area).

TABLE I: EXPERIMENTAL CONDITIONS AND RESPONSE VALUES (NUMBER OF PEAKS AND TOTAL AREA) OBTAINED IN THE OPTIMIZATION OF ISOLATION OF VOLATILE COMPOUNDS FROM WHOLE BANANA FRUITS BY HS-SPME.

\begin{tabular}{ccccccc}
\hline \multirow{2}{*}{ Assays } & \multicolumn{2}{c}{ Coded factors } & \multicolumn{2}{c}{ Decoded factors } & \multicolumn{2}{c}{ Response variables } \\
\cline { 2 - 7 } & $T_{e q}$ & $T_{\exp }$ & $T_{e q}(\min )$ & $T_{\exp }(\min )$ & Peaks & Total area \\
\hline 1 & -1.00 & -1.00 & 90.00 & 90.00 & 35 & $1.41 \mathrm{E}+09$ \\
2 & -1.00 & 1.00 & 90.00 & 150.00 & 43 & $1.17 \mathrm{E}+09$ \\
3 & 1.00 & -1.00 & 180.00 & 90.00 & 33 & $1.08 \mathrm{E}+09$ \\
4 & 1.00 & 1.00 & 180.00 & 150.00 & 42 & $1.07 \mathrm{E}+09$ \\
5 & -1.41 & 0.00 & 71.36 & 120.00 & 47 & $2.19 \mathrm{E}+09$ \\
6 & 1.41 & 0.00 & 198.64 & 120.00 & 59 & $2.24 \mathrm{E}+09$ \\
7 & 0.00 & -1.41 & 135.00 & 77.57 & 40 & $2.23 \mathrm{E}+09$ \\
8 & 0.00 & 1.41 & 135.00 & 162.43 & 57 & $1.27 \mathrm{E}+09$ \\
$9(\mathrm{C})$ & 0.00 & 0.00 & 135.00 & 120.00 & 55 & $2.77 \mathrm{E}+09$ \\
10 (C) & 0.00 & 0.00 & 135.00 & 120.00 & 83 & $3.27 \mathrm{E}+09$ \\
$11(\mathrm{C})$ & 0.00 & 0.00 & 135.00 & 120.00 & 76 & $3.34 \mathrm{E}+09$ \\
\hline$T_{e q}=$ equilibrium time; $T_{\exp }=$ fiber exposure time; $(C)=$ central point
\end{tabular}

TABLE II: EXPERIMENTAL CONDITIONS AND RESPONSE VALUES (NUMBER OF PEAKS AND TOTAL AREA) OBTAINED IN THE OPTIMIZATION OF ISOLATION OF VOLATILE COMPOUNDS FROM BANANA PULP BY HS-SPME.

\begin{tabular}{ccccccc}
\multirow{2}{*}{ Assays } & \multicolumn{2}{c}{ Coded factors } & \multicolumn{2}{c}{ Decoded factors } & \multicolumn{2}{c}{ Response variables } \\
\cline { 2 - 7 } & $T_{e q}$ & $T_{\exp }$ & $T_{e q}(\min )$ & $T_{\exp }(\min )$ & Peaks & Total area \\
\hline 1 & -1.00 & -1.00 & 5.00 & 20.00 & 23 & $4.75 \mathrm{E}+08$ \\
2 & -1.00 & 1.00 & 5.00 & 100.00 & 42 & $7.32 \mathrm{E}+08$ \\
3 & 1.00 & -1.00 & 25.00 & 20.00 & 15 & $3.82 \mathrm{E}+08$ \\
4 & 1.00 & 1.00 & 25.00 & 100.00 & 28 & $4.45 \mathrm{E}+08$ \\
5 & -1.41 & 0.00 & 0.86 & 60.00 & 24 & $3.81 \mathrm{E}+08$ \\
6 & 1.41 & 0.00 & 29.14 & 60.00 & 29 & $4.58 \mathrm{E}+08$ \\
7 & 0.00 & -1.41 & 15.00 & 3.43 & 11 & $2.96 \mathrm{E}+08$ \\
8 & 0.00 & 1.41 & 15.00 & 116.57 & 41 & $1.16 \mathrm{E}+09$ \\
$9(\mathrm{C})$ & 0.00 & 0.00 & 15.00 & 60.00 & 59 & $1.99 \mathrm{E}+09$ \\
$10(\mathrm{C})$ & 0.00 & 0.00 & 15.00 & 60.00 & 51 & $8.74 \mathrm{E}+08$ \\
$11(\mathrm{C})$ & 0.00 & 0.00 & 15.00 & 60.00 & 52 & $8.31 \mathrm{E}+08$ \\
\hline
\end{tabular}

Teq = equilibrium time; $T \exp =$ fiber exposure time; $(C)=$ central point

\section{E. Statistical Analysis}

A polynomial regression model was used to express the relation between the levels of quantitative factors (equilibrium and exposure times) and response variables. The quality of fit was expressed by the coefficient of determination $\left(\mathrm{R}^{2}\right)$ and lack of fit test. Statistical significance was determined by the F-test and response surfaces were constructed from the regression equations. The Statistica version 7.1 (Statsoft Inc., Tulsa, OK, USA) software was used for this purpose.

\section{RESUlTS AND DISCUSSION}

Fig. 2 shows the influence of the temperature during isolation of volatiles from banana pulp. It was observed that when the temperature was increased, there was a decrease in the abundance of volatiles. Therefore, the temperature was not included in the model, and $25^{\circ} \mathrm{C}$ was fixed as the optimal temperature. 


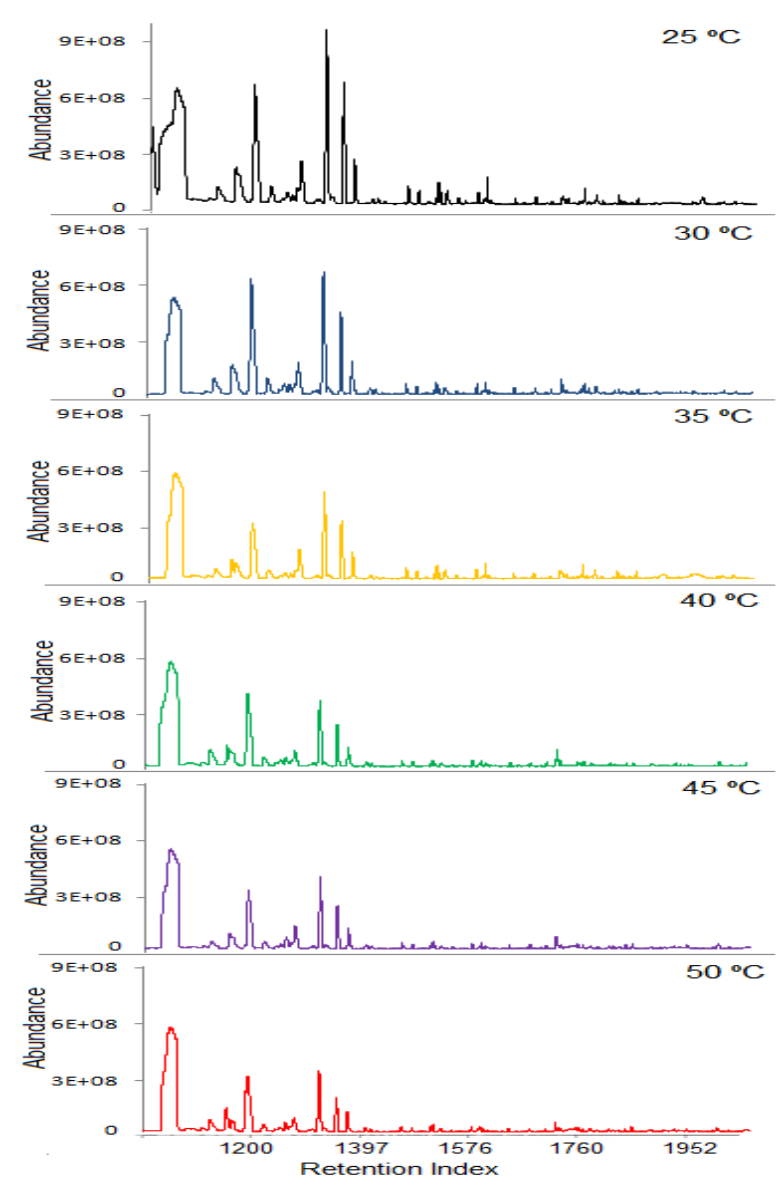

Fig. 2. Cromatograms previously obtained by increasing the temperature for the optimization with PDMS fiber by HS-SPME.

In this study, the criteria for optimization of the isolation of volatiles of banana were higher number of peaks and greater total area of the chromatogram, which was assessed by chromatographic analysis at each assay of the experimental design. Tables I and II show the response values obtained for the combinations of $T_{e q}$ and $T_{\text {exp }}$, for whole fruits and banana pulp samples, respectively. Abundance of peaks (number and area) for the whole fruit was greater than for the banana pulp in almost every assay. These differences could be caused by the greater amount of sample used for the whole fruit.

The statistical significance of regression and lack of fit of the model and the coefficient of determination $\left(R^{2}\right)$ were tested. The first parameter was observed from the value calculated using the Fisher distribution (F-test) determined by the ratio of the mean square regression and mean square of the residue. Thus, a statistically significant value of this ratio must be greater than the tabulated value for $\mathrm{F}$. The second parameter was obtained by the ratio of the mean square of lack of fit and pure error. In addition, the coefficient of determination $\left(R^{2}\right)$ can be interpreted as the proportion of variation in the response variable explained by the model. The regression equations found for the response variables were defined as follows:

$$
\begin{aligned}
& z=-294.718+1.655 x-0.006 x^{2}+4.024 y-0.016 y^{2}+ \\
& 0.0002 x y \\
& \quad z=-15337.73+81.01 x-0.32 x^{2}+224.42 y-0.99 y^{2}+ \\
& 0.04 x y
\end{aligned}
$$

$$
\begin{aligned}
& z=-22.124+4.107 x-0.135 x^{2}+1.325 y-0.009 y^{2}- \\
& 0.004 x y \\
& z=-670.979+130.698 x-4.226 x^{2}+26.809 y-0.168 y^{2}- \\
& 0.122 x y
\end{aligned}
$$

where $x$ is equilibrium time, $y$ is exposure time and $z$ is the response variable.

The analysis of variance (ANOVA) table for validation of models [12], [13] for whole fruits can be seen in Table III (number of peaks) and Table IV (total area). Regression model for the number of peaks (1) was not statistically significant $\left(F_{\text {calculated }}<F_{\text {tabulated }}\right)$, but the regression obtained for total area (2) was significant at $10 \%\left(F_{\text {calculated }}>F_{\text {tabulated }}\right)$ indicating the existence of an appropriate model for the variable studied. Both models did not present evidence of significant lack of fit.

ANOVA results for banana pulp can be seen in Table $\mathrm{V}$ (numbers of peaks) and Table VI (total area). For this experiment, the regression model for the number of peaks (3) was significant at $5 \%$, and was not significant for total area (4). However, it can also be seen that the models did not present evidence of significant lack of fit for the response variable, showing that they can be accepted as providing an adequate representation of the data [12].

TABLE III: ANALYSIS OF VARIANCE OF REGRESSION MODEL FOR NUMBER of Chromatographic PEAKS OF BANANA Whole Fruits Volatile

\begin{tabular}{lcccccc}
\multicolumn{7}{c}{ COMPOUND ISOLATED BY HS-SPME } \\
\hline SV & SS & DF & MS & $F_{\text {calc }}$ & $F_{5 \%}$ & $F_{10 \%}$ \\
\hline Regression & 2282.51 & 5 & 456.50 & 2.88 & 5.05 & 3.45 \\
Residues & 793.22 & 5 & 158.64 & & & \\
Lack of fit & 368.55 & 3 & 122.85 & 0.58 & 19.16 & \\
Pure error & 424.67 & 2 & 212.33 & & & \\
Total & 3075.73 & 10 & & & & \\
$R^{2}$ & 0.70 & & & & & \\
\hline
\end{tabular}

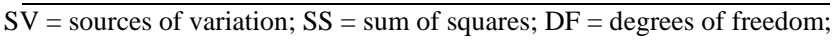
MS = mean of squares; $F_{\text {calc }}=F$-value calculated; $F=F$-value tabulated at $\alpha$ $=5 \%$ or $10 \% ; R^{2}=$ coefficient of determination

TABLE IV: ANALYSIS OF VARIANCE OF REGRESSION MODEL FOR TOTAL AREA IN THE CHROMATOGRAMS OF BANANA WHOLE FRUITS VOLATILE COMPOUNDS ISOLATED BY HS-SPME

\begin{tabular}{lcccccc}
\hline \multicolumn{1}{c}{$\mathrm{SV}$} & $\mathrm{SS}$ & $\mathrm{DF}$ & $\mathrm{MS}$ & $F_{\text {calc }}$ & $F_{5 \%}$ & $F_{10 \%}$ \\
\hline Regression & $7.23 \mathrm{E}+18$ & 5 & $1.45 \mathrm{E}+18$ & 4.36 & 5.05 & 3.45 \\
Residues & $1.66 \mathrm{E}+18$ & 5 & $3.31 \mathrm{E}+17$ & & & \\
Lack of fit & $1.47 \mathrm{E}+18$ & 3 & $4.89 \mathrm{E}+17$ & 5.09 & 19.16 & \\
Pure error & $1.92 \mathrm{E}+17$ & 2 & $9.59 \mathrm{E}+16$ & & & \\
Total & $8.88 \mathrm{E}+18$ & 10 & & & & \\
$R^{2}$ & 0.78 & & & & & \\
\hline
\end{tabular}

$\mathrm{SV}=$ sources of variation; $\mathrm{SS}=$ sum of squares; $\mathrm{DF}=$ degrees of freedom; MS = mean of squares; $F_{\text {calc }}=F$-value calculated; $F=F$-value tabulated at $\alpha$ $=5 \%$ or $10 \% ; R^{2}=$ coefficient of determination

TABLE V: ANALYSIS OF VARIANCE OF REGRESSION MODEL FOR NUMBER OF CHROMATOGRAPHIC PEAKS OF BANANA PULP VOLATILE COMPOUNDS ISOLATED BY HS-SPME

\begin{tabular}{lcccccc}
\hline \multicolumn{1}{c}{ SV } & SS & DF & MS & $F_{\text {calc }}$ & $F_{5 \%}$ & $F_{10 \%}$ \\
\hline Regression & 2845.37 & 5 & 569.07 & 17.97 & 5.05 & 3.45 \\
Residues & 158.35 & 5 & 31.67 & & & \\
Lack of fit & 120.35 & 3 & 40.12 & 2.11 & 19.16 & \\
Pure error & 38.00 & 2 & 19.00 & & & \\
Total & 3003.73 & 10 & & & & \\
$R^{2}$ & 0.94 & & & \\
SV = sources of variation; $\mathrm{SS}=$ sum of squares; $\mathrm{DF}=$ degrees of freedom; & \\
$\mathrm{MS}=$ mean of squares; $F_{\text {calc }}=F$-value calculated; $F=F$-value tabulated at $\alpha$ \\
$=5 \%$ or $10 \% ; R^{2}=$ coefficient of determination
\end{tabular}


TABLE VI: ANALYSIS OF VARIANCE OF REGRESSION MODEL FOR TOTAL AREA IN THE CHROMATOGRAMS OF BANANA Pulp Volatile COMPOUNDS

\begin{tabular}{lcccccc}
\multicolumn{7}{c}{ ISOLATED BY HS-SPME } \\
\hline \multicolumn{1}{c}{ SV } & SS & DF & MS & $F_{\text {calc }}$ & $F_{5 \%}$ & $F_{10 \%}$ \\
\hline Regression & $1.73 \mathrm{E}+18$ & 5 & $3.46 \mathrm{E}+17$ & 1.72 & 5.05 & 3.45 \\
Residues & $1.01 \mathrm{E}+18$ & 5 & $2.01 \mathrm{E}+17$ & & & \\
Lack of fit & $1.39 \mathrm{E}+17$ & 3 & $4.64 \mathrm{E}+16$ & 0.11 & 19.16 & \\
Pure error & $8.66 \mathrm{E}+17$ & 2 & $4.33 \mathrm{E}+17$ & & & \\
Total & $2.74 \mathrm{E}+18$ & 10 & & & & \\
$R^{2}$ & 0.59 & & & & & \\
\hline
\end{tabular}

$\mathrm{SV}=$ sources of variation; $\mathrm{SS}=$ sum of squares; $\mathrm{DF}=$ degrees of freedom; $\mathrm{MS}=$ mean of squares; $F_{\text {calc }}=F$-value calculated; $F=F$-value tabulated at $\alpha$ $=5 \%$ or $10 \% ; R^{2}=$ coefficient of determination

The contour plots of the response surfaces were the starting point for the establishment of optimal conditions for volatile isolation by HS-SPME. For whole fruits samples (Fig. 3), the optimal values found for the equilibrium and exposure times were 140 and $120 \mathrm{~min}$, respectively. For banana pulp (Fig. 4), $15 \mathrm{~min}$ for equilibrium time and $60 \mathrm{~min}$ for exposure time were situated in the region of higher response values. It was also observed that, for the whole fruit, the time required for the headspace to reach equilibrium was higher than the fiber exposure time needed to extract the volatiles, and for the banana pulp it was otherwise. This was probably because of the large volume of the recipient used in the whole fruit experiment, increasing the time taken for the volatiles coming from the whole fruit to get into equilibrium with the gas phase. In the pulp experiment, apart from the fact that the headspace volume was much lower, the agitation seemed to reduce the equilibrium time.
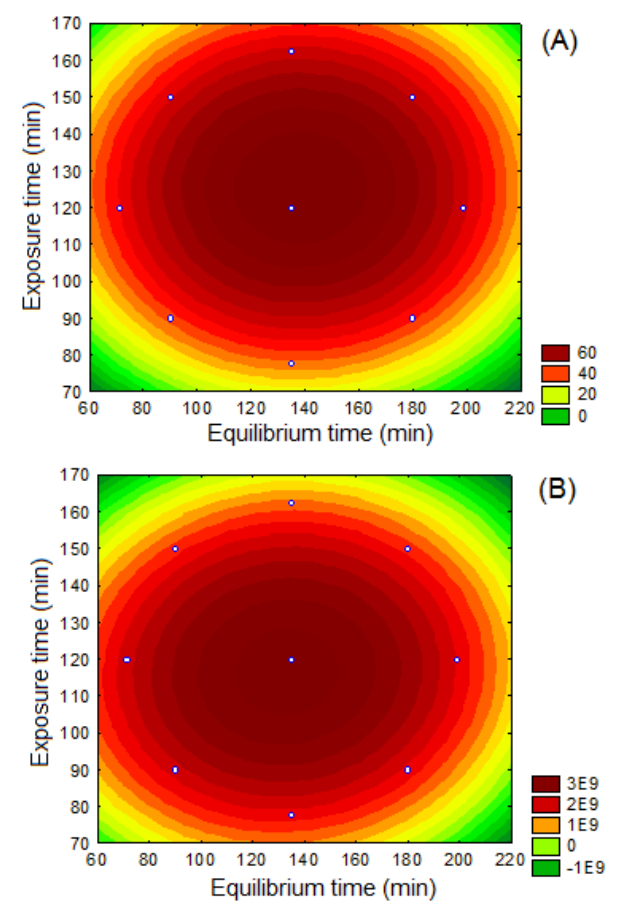

Fig. 3. Response surfaces obtained for the number of peaks (A) and total area (B) in the chromatograms in the optimization of the isolation of the volatile compounds from the whole banana fruit by HS-SPME.

Fig. 5 and Fig. 6 show the chromatograms obtained by GC-MS with the identification of the majority of volatiles compounds of the green and ripe banana (Musa acuminata), respectively, using the optimized conditions in both methodologies: whole fruit and banana pulp. It was observed that for green fruit, the pulp had predominance of aldehydes and alcohols, while the whole fruit had predominance of terpenes. The terpenes are biosynthesized from primary metabolites [14] with the isopentenyl-diphosphate (IPP) as the basic unit active in its formation. The IPP can be formed from intermediates of the glycolysis cycle or photosynthetic carbon reduction, through a series of reactions called route methylerythritol phosphate (MEP), which occurs in chloroplasts and plastids, which in the case of banana are present in the skin. For this reason, only in the green fruits of the whole fruit analysis it was possible to identify the terpenes. On the other hand, the ripe fruits showed predominance of esters and similar qualitative volatile profiles in both samples (whole fruit and pulp).
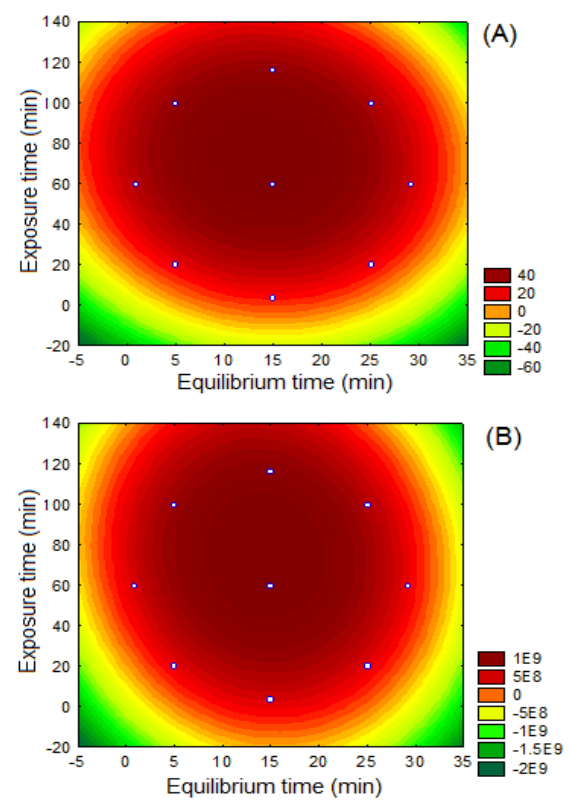

Fig. 4. Response surfaces obtained for the number of peaks (A) and total area (B) in the chromatograms in the optimization of the isolation of the volatile compounds from the banana pulp by HS-SPME.

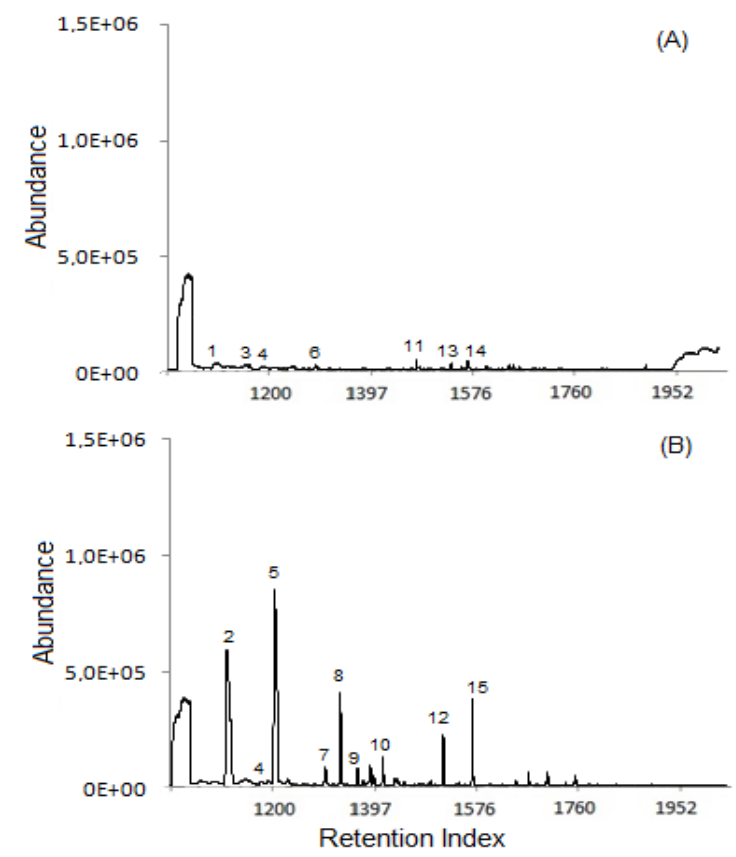

Fig. 5. Chromatogram from green fruit (with 7 days after harvest), obtained by GC-MS, with the identification of the majority of volatiles compounds from the whole fruit (A) and banana pulp (B) in optimized conditions. Peak identification: (1) $\alpha$-pinene, (2) Hexanal, (3) m-Xylene, (4) Limonene, (5) 2-Hexenal, (6) Z-Ocimene, (7) E-2-Heptenal, (8) 1-Hexanol, (9) 3-Hexen-1-ol, (10) E-2-Hexen-1-ol, (11) 2-Ethyl-1-hexanol, (12) E-2-Nonenal, (13) $\alpha$-Cedrene, (14) $\beta$-Cedrene and (15) 2,6-Nonadienal. 


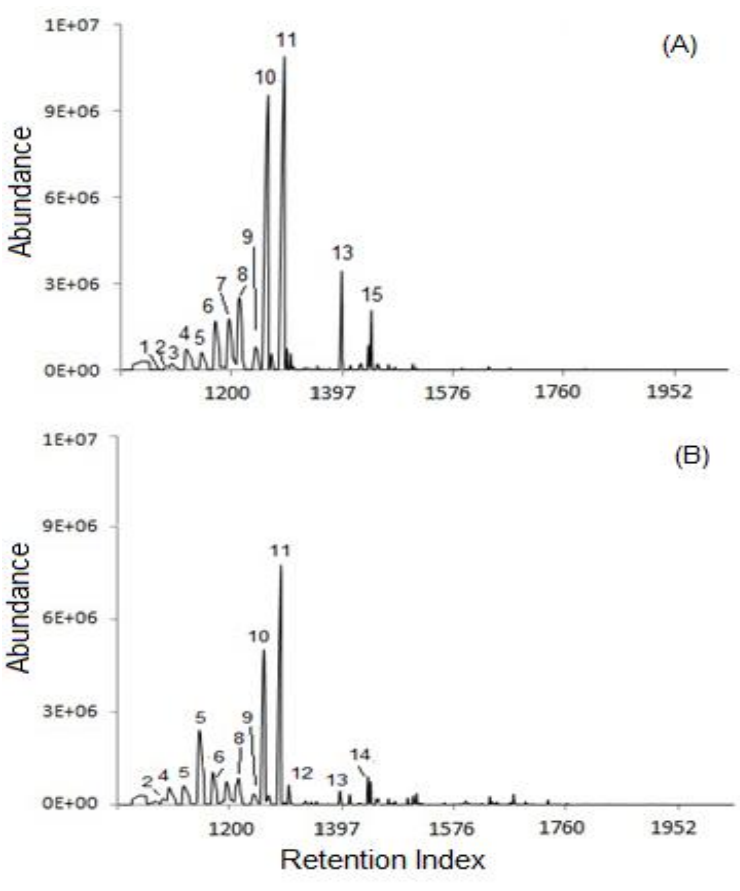

Fig. 6. Chromatogram from ripe fruit (with 16 days after harvest), obtained by GC-MS, with the identification of the majority volatiles compounds from whole fruit (A) and banana pulp (B) in the optimized conditions. Peak identification: (1) ethyl acetate, (2) 2-pentanone, (3) 2-methylpropyl acetate, (4) 2-pentanol acetate, (5) 3-methyl-1-butanol acetate, (6) 2-methylpropyl butanoate, (7) 2-methylpropyl 3-methylbutanoate, (8) butyl butanoate, (9) butyl pentanoate, (10) 3-methylbutyl butanoate, (11) 3-methylbutyl 3-methylbutanoate, (12) 2-heptanol, (13) 1-methylhexyl butanoate, (14) hexyl 3-methylbutanoate and (15) 3-methylcyclohexanol.

\section{ACKNOWLEDGMENT}

We thank Anna Clara Cunico Montel for helping with the representative design of the isolation of banana volatiles by HS-SPME (Fig. 1), and Prof. Eduardo Purgatto, Helena Chiebao and Tatiana Toledo for the banana samples.

\section{REFERENCES}

[1] M. J. Jordan, K. Tandon, P. E. Shaw, and K. L. Goodner, "Aromatic profile of aqueous banana essence and banana fruit by gas chromatography - mass spectrometry (GC-MS) and gas chromatography-olfactometry (GC-O)," Journal of Agricultural and Food Chemistry, vol. 49, pp. 4813-4817, Aug. 2001.

[2] J. C. Fioravanço, "Mercado mundial da banana: produção, comércio e participação brasileira," Informações Econômicas, vol. 33, no. 10, pp. 15-27, Oct. 2003.

[3] M. Thomazini and M. R. B. Franco, "Metodologia para análise dos constituintes voláteis do sabor," Boletim da sb CTA, vol. 34, no. 1, pp. $52-59,2000$

[4] C. L. Arthur and J. Pawliszyn, "Solid-phase microextraction with thermal desorption using fused silica optical fibers," Analytical Chemistry, vol. 62, pp. 2145-2148, Oct. 1990.

[5] E. Ibáñez, S. L. Sebástian, E. Ramos, J. Tabera, and G. Reglero, "Analysis of volatile fruit components by headspace solid-phase microextraction," Food Chemistry, vol. 63, no. 2, pp. 281-286, Oct., 1998.

[6] X. Yang and T. Peppard, "Solid-phase microextraction for flavor analysis," Journal of Agriculture and Food Chemistry, vol. 42, pp. 1925-1930, Aug. 1994.

[7] S. B. Junior, A. M. T. Melo, C. A. Zini, and H. T. Godoy, "Optimization of the extraction conditions of the volatile compounds from chili peppers by headspace solid phase micro-extraction," Journal of Chromatography. A, vol. 1218, no.21, pp. 3345-3350, May 2011.

[8] R. Wagner and M. R. B. Franco, "Effect of the variables time and temperature on volatile compounds extraction of salami by solid phase microextraction," Food Analytical Methods, vol. 5, pp.1186-1195, Oct. 2012.
[9] D. C. Montgomery, Design and Analysis of Experiments: Response Surface Method and Designs, 4th ed., New Jersey: John Wiley and Sons, Inc., ch. 1, 2005.

[10] T. Liu and T. Yang, "Optimization of solid-Phase microextraction analysis for studying change of headspace flavor compounds of banana during ripening," Journal of Agricultural and Food Chemistry, vol. 50, pp. 653-657, Jan. 2002.

[11] S. A. Mjos, S. Meier, and S. Boitsov, "Alkylphenol retention indices," Journal Chromatography A, vol. 1123, pp. 98-105, May 2006.

[12] S. L. C. Ferreira, R. E. Bruns, E. G. P. Silva, W. N. L. Santos, C. M Quintella, J. M. David, J. B. Andrade, M. C. Breitkreitz, I. C. S. F. Jardim, and B. B. Neto, "Statistical designs and response surface techniques for the optimization of chromatographic systems," Journal of Chromatography A, vol. 1158, pp. 2-14, July 2007.

[13] M. I. Rodrigues and A. F. Iemma, Planejamento de Experimentos e Otimização de Processos, 1th ed, Campinas, SP: Editora Casa do Pão, pp. 326, 2005.

[14] L. Taiz and E. Zeiger, Plant Physiology, 3 th ed, Sinauer Assoc., pp. $690,2002$.

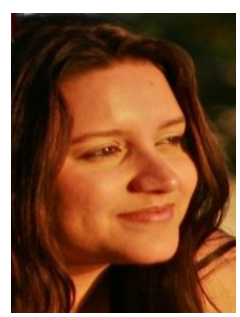

Heliofábia Virgínia de Vasconcelos Facundo was born in Fortaleza, Brazil, 1983, she is a food engineer with a master`s degree in Food Science and Technology (Federal University of Ceará - UFC, 2009) and is currently a PhD student in Food Science in the Faculty of Pharmaceutical Sciences in the University of Sao Paulo - USP, Brazil. She has published a book chapter about Sensory Evaluation in Fruit Product Development In: Advances in Fruit Processing Technologies. Boca Raton: CRC, 2012 and some original papers in international conferences and journals. Her research interests include fruit quality under cold storage conditions, proteomics, sensory analysis and multivariate statistical methods. M Sc. Facundo is a member of the Brazilian Mass Spectrometry Society ( $\mathrm{Br}$ MASS), Brazilian Society of Proteomics (Br Prot) and participates in some projects promoted by the Brazilian Agricultural Research Corporation (EMBRAPA)

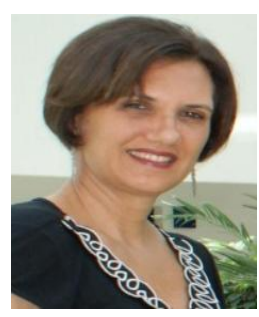

Deborah dos Santos Garruti was born in Woodland, USA, 1962, she is a food engineer, with a master's degree in Food Technology (State University of Campinas - UNICAMP, 1989) and Ph.D. in Food Science (UNICAMP, 2000). She is a researcher at the Brazilian Agricultural Research Corporation (EMBRAPA) in Fortaleza, Brazil, and is the Head of the Laboratory of Sensory Analysis and Aroma Research (gas chromatography - mass spectrometry and olfactometry). She is also a Professor at the Federal University of Ceará (Food Technology Department) where she teaches for post-graduation programs and at the State University of Ceará (Food Nutrition and Chemistry Departments). She has published 50 original papers in national and international journals, 40 full papers in conferences, 135 abstracts in conference proceedings, 2 books, 8 book chapters and is a reviewer of national and international journals. Her research interests include the characterization of the volatile profiles of new varieties of tropical fruits and other raw materials, the effect of processing on the compounds responsible for their flavor, and natural essences of tropical fruit, as well as sensory analysis in the development of new products, technologies and quality control.

Dr. Garruti is member of the Brazilian Society of Food Science and Technology (SBCTA) and the International Society for Horticultural Sciences (ISHS). She is a collaborator in the National Council of Scientific and Technological Development (Ministry of Science, Technology and Innovation) acting as an ad hoc consultant for analyses of sponsorship and scholarship applications.

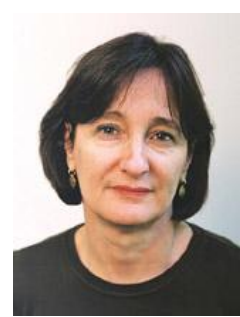

Beatriz Rosana Cordenunsi was born in Alto Paraná, Brazil, 1954, she has a degree in chemistry from the State University of Maringá (1976), master's degree in Food Science from the State University of Londrina (1983) and $\mathrm{PhD}$ in Food Science from the University of São Paulo - USP (1989). She is a Full Professor and Head of the Department of Food and Experimental Nutrition in the Faculty of Pharmaceutical Sciences at USP, Brazil. She has published over 50 original research articles in national and international journals, 14 full papers in conferences, 
over 80 abstracts in conference proceedings, 6 book chapters and is a reviewer for national and international journals and periodicals. Her research interests include composition of carbohydrates in foods and biochemistry of post-harvest fruits. Dr. Cordenunsi is the coordinator of the Food and Nutrition Research Center (NAPAN), Brazil.

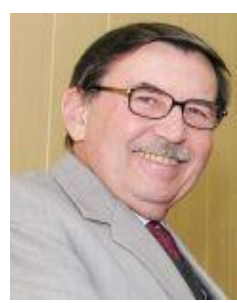

Franco Maria Lajolo graduated in Pharmacy and Biochemistry at the University of São Paulo - USP (1965), obtained his doctorate in Food Science at the USP (1969) and was a post-doctoral fellow at the Massachusetts Institute of Technology (1971). He was the Vice-Rector of the University of São Paulo (2006-2010), has published over 240 original research articles in national and international journals, 70 full papers in conferences, around 400 abstracts published in conference proceedings, 8 books and 40 book chapters and is a reviewer for international journals and periodicals. In more than 120 conferences, he was the member of the scientific committee and /or the speaker. Currently, he is Full Professor in the Faculty of Pharmaceutical Sciences at USP, Brazil, and has experience in the area of Food Science and Technology with an emphasis on Chemistry, Food Biochemistry and Ripening Molecular Biology. He is currently working on the following subjects: functional foods, biological and structural characterization of bioactive compounds and molecular biology.

Dr. Lajolo is a member of the NAPAN (Food and Nutrition Research Center, Brazil), advisor of the Brazilian Society of Food Science and Technology (SBCTA) and international coordinator of the Cooperation Project in the Program of Science and Technology for Development (CYTED). He is also member of the Scientific Technical Advisory Committee on Functional Foods and Novel Foods (CTCAF) of the National Agency of Sanitary Surveillance of the Ministry of Health and a member of the Academy of Sciences of the State of São Paulo. 